This item was submitted to Loughborough's Research Repository by the author.

Items in Figshare are protected by copyright, with all rights reserved, unless otherwise indicated.

\title{
Iron solubilization during anaerobic growth of acidophilic microorganisms with a polymetallic sulfide ore
}

PLEASE CITE THE PUBLISHED VERSION

http://dx.doi.org/10.1016/j.mineng.2014.12.004

\section{PUBLISHER}

(C) Elsevier

VERSION

VoR (Version of Record)

\section{PUBLISHER STATEMENT}

This work is made available according to the conditions of the Creative Commons Attribution-NonCommercialNoDerivatives 4.0 International (CC BY-NC-ND 4.0) licence. Full details of this licence are available at: https://creativecommons.org/licenses/by-nc-nd/4.0/

\section{LICENCE}

CC BY-NC-ND 4.0

\section{REPOSITORY RECORD}

Norris, Paul R., Oliver Gould, and Thomas J. Ogden. 2019. "Iron Solubilization During Anaerobic Growth of Acidophilic Microorganisms with a Polymetallic Sulfide Ore". figshare. https://hdl.handle.net/2134/20007. 


\section{Iron solubilization during anaerobic growth of acidophilic microorganisms with a polymetallic sulfide ore}

Paul R. Norris ${ }^{*}$, Oliver J.P. Gould ${ }^{1}$, Thomas J. Ogden ${ }^{2}$

School of Life Sciences, University of Warwick, Coventry CV4 7AL, UK

* Corresponding author at: Environment and Sustainability Institute, University of Exeter, Penryn Campus, Penryn, Cornwall TR10 9FE, UK. Tel.: +4401326 259482.

E-mail addresses: P.Norris@exeter.ac.uk (P.R. Norris), O.J.Gould@lboro.ac.uk (O.J.P.Gould).

1 Present address: Wolfson School of Mechanical and Manufacturing Engineering, Loughborough University, Leicestershire LE11 3TU, UK.

2 Present address: King’s High School, Smith Street, Warwick, Warwickshire CV34 4HJ, UK.

Keywords: Ore leaching, microbial iron reduction, anaerobic sulfur oxidation

\section{Abstract}

Acidithiobacillus ferrooxidans at $30^{\circ} \mathrm{C}$ and Sulfobacillus thermosulfidooxidans at $47^{\circ} \mathrm{C}$ were selected from a preliminary screening of various acidophiles for their ferric iron reduction capacities during anaerobic, autotrophic growth on sulfur. The selected cultures were used with a polymetallic sulfide ore under anoxic conditions to demonstrate enhanced solubilization of iron during leaching in shaken flasks and enhanced removal of iron from laboratory ore-leaching columns, compared to leaching with continuous aeration. Oreassociated, ferric iron-rich precipitates, which were formed under previously oxidizing conditions, were a potential influence on extraction of target metals and percolation through ore columns and were available as the source of ferric iron for anaerobic sulfur oxidation. Over twice as much iron was removed by moderate thermophiles when anoxic phases were introduced during the leaching. Enhanced removal of iron and some improvement in extraction of base metals from ore fragments were also demonstrated with a selected “'Sulfolobus"'-like strain during growth and leaching with alternating periods of aeration and anoxic conditions at $70^{\circ} \mathrm{C}$.

\section{Introduction}

Brock and Gustafson (1976) speculated that anaerobic, microbial oxidation of sulfur using ferric iron as the electron acceptor may occur in oxygen-limited interiors of copper leach dumps. They noted that Acidithiobacillus ferrooxidans growing anaerobically reduced ferric iron in the presence of sulfur, although no data were presented. Reduction of ferric iron during sulfur oxidation aerobically by Acidithiobacillus 
thiooxidans was also described (Brock and Gustafson, 1976). Anaerobic growth of At. ferrooxidans with sulfur and ferric iron was subsequently quantified (Pronk et al., 1992; Das et al., 1992). Leaching of zinc from a sulfide occurred with At. ferrooxidans in the absence of oxygen, with a mixture of ferrous and ferric iron in solution (Goodman et al., 1983). Zinc leaching was not as extensive as that seen with aeration, but more iron remained in solution under anoxic conditions. Progressive solubilization of copper from covellite occurred during anaerobic growth of At. ferrooxidans in the presence of ferric iron (Donati et al., 1997). This contrasted with limited solubilization in the absence of bacteria and was attributed to anaerobic oxidation of sulfur that became enriched at the mineral surface (Donati et al., 1997).

The precipitation of iron compounds during leaching of copper ore in laboratory percolation columns increased with an increase in temperature (Norris et al., 2012a). In ore columns with an iron-rich polymetallic sulfide ore and moderately thermophilic bacteria, iron precipitation in some cases restricted the percolation and it was suggested that precipitates coating ore fragments might also directly restrict leaching at high temperature (Norris et al., 2012b). The anaerobic growth of several moderately thermophilic, iron- and sulfur-oxidizing acidophiles (Bridge and Johnson, 1998) has been described. Ferrous iron was produced during dissolution of amorphous ferric hydroxide, jarosite and goethite by one strain of Sulfobacillus acidophilus while other moderate thermophiles showed little anaerobic activity with these iron sources. Glycerol was used as the electron donor for iron reduction (Bridge and Johnson, 1998). Glycerol was also used with moderate thermophiles anaerobically to remove jarosite from a chalcopyrite concentrate residue, which had been previously partly leached during aerobic growth of the moderate thermophiles (Stott et al., 2000). The removal of jarosite, which was not complete, did not result in a higher yield of copper when the treated residue was leached again under aeration. The potential of moderate thermophiles to reduce ferric iron in the absence of organic supplements was shown by some limited ferrous iron production during growth of some strains of Sb. acidophilus and Sulfobacillus thermosulfidooxidans with tetrathionate as electron donor (Bridge and Johnson, 1998); otherwise the anaerobic, autotrophic growth of thermophiles with mineral sulfides has received limited investigation. When conditions during copper ore leaching by moderate thermophiles in a percolation column were switched from aerated to anoxic, the population was found to comprise Sb. thermosulfidooxidans in contrast to an "Acidithiomicrobium”' and Acidimicrobium ferrooxidans-dominated population with continuing aeration (Norris et al., 2012a). This study used a polymetallic sulfide ore from the heap leach operation at the Talvivaara mine, Finland (Riekkola-Vanhanen, 2013) to investigate the solubilization of iron during bioleaching under aerated and anoxic conditions.

\section{Materials and methods}

\subsection{Mineral sulfide ore}

A sample of ore fragments prepared for heap leaching at the Talvivaara mine (Sotkamo, Finland) was provided and contained (\% w/w) nickel (0.26), zinc (0.49), copper (0.19) and iron (9.4). A sample of part-leached ore from a heap 
was also provided and contained (\% w/w) nickel (0.20), zinc (0.38), copper (0.21) and iron (10.9). Precipitated iron compounds were evident on the surface of the part-leached ore fragments.

\subsection{Microorganisms}

Cultures used at $30{ }^{\circ} \mathrm{C}$ were the salt-tolerant, sulfur-oxidizing “Acidithiobacillus" strain V1 (Simmons and Norris, 2002) and type strains of At. ferrooxidans (ATCC 23270) and At. thiooxidans (ATCC 8085).

Moderately thermophilic acidophiles used were the Sb. thermosulfidooxidans type strain (DSM 9293); a Sb. thermosulfidooxidans strain isolated in pure culture from a mixed culture in a laboratory bioreactor which was fed with a copper concentrate at $48{ }^{\circ} \mathrm{C}$ (Norris, unpublished work); the type strain of Sb. acidophilus (DSM 10332); “'Sulfobacillus G1”, a novel species related to Sb. acidophilus, but capable of growth at higher temperature (Norris, unpublished work); the iron- and sulfur-oxidizing “'Acidithiomicrobium” strain P2'” (Davis-Belmar and Norris, 2009; Norris et al., 2011); the type strain of Acidithiobacillus caldus (DSM 8584); a pyrite enrichment culture established at $47^{\circ} \mathrm{C}$ with bacteria associated with the part-leached Talvivaara ore.

Several pure and enrichment cultures of thermoacidophilic archaea were examined. These were the ICHT culture, previously used in pilot plants processing chalcopyrite (Norris et al., 2013); an “Acidianus"'-related thermophile isolated from a Montserrat hot spring (previously noted as clone MS2, Burton and Norris, 2000); “'Metallosphaera”' strain J1 (Norris et al., 2013); the uncharacterized “'Sulfolobus”'-like strain J2 from a Java hot spring (Norris, unpublished work); and pyrite-enrichment cultures from other geothermal sites. Cultures were transferred from growth as aerated cultures with pyrite to growth with elemental sulfur and ferric iron in shaken, sealed flasks at $75{ }^{\circ} \mathrm{C}$ with atmospheres of $5 \% \mathrm{v} / \mathrm{v} \mathrm{CO} \mathrm{CO}_{2}$ in $\mathrm{N}_{2}$. Cultures were then sub-cultured twice with sulfur/ferric iron before the activity was followed as production of ferrous iron.

\subsection{Anaerobic growth of acidophiles with sulfur and ferric iron}

The mineral salts medium contained $\left(\mathrm{g} \mathrm{l}^{-1}\right) \mathrm{MgSO} 4 \cdot 7 \mathrm{H}_{2} \mathrm{O}(0.5)$, (NH4)2SO4 (0.4) and $\mathrm{K}_{2} \mathrm{HPO}_{4}(0.2)$. Sulfur was added at $5 \mathrm{~g} \mathrm{l}^{-1}$. The $\mathrm{pH}$ was not adjusted but reached a suitable $\mathrm{pH}$ for the acidophiles (about $\mathrm{pH} 2$ ) after addition of ferric iron ( $50 \mathrm{mM}$, from $5 \% \mathrm{v} / \mathrm{v}$ of $0.5 \mathrm{M}$ ferric sulfate) as the electron acceptor for the anaerobic oxidation of the sulfur and after the addition of the inocula $(5 \% \mathrm{v} / \mathrm{v})$. The medium $(100 \mathrm{ml}$ in flasks of $300 \mathrm{ml}$ volume) was gassed with $5 \% \mathrm{v} / \mathrm{v} \mathrm{CO} 2$ in $\mathrm{N}_{2}$ for $30 \mathrm{~min}$ before the ferric sulfate was added and for another $30 \mathrm{~min}$ afterwards before inoculation. Flasks were sealed with SubaSeals (Sigma), through which they were inoculated and through which samples could be taken with syringe needles. The initial cell number of each strain following

inoculation was predicted to be approximately $10^{6} \mathrm{ml}^{-1}$, following measurement of the cell concentration in the inocula using a CellFacts particle analyser (CellFacts 2014, Coventry, UK). Ferrous iron in solution was measured by titration against ceric sulfate with 1,10-phenanthroline ferrous complex (Fisher Scientific) as indicator. 
2.4 Shaken flasks with secondary (part leached) ore at $30^{\circ} \mathrm{C}$

The mineral salts medium and flasks were as given above, except for an initial adjustment to $\mathrm{pH} 2$ with $\mathrm{H}_{2} \mathrm{SO}_{4}(5 \% \mathrm{v} / \mathrm{v}) .10 \mathrm{~g}$ of the part-leached ore with a size range of solids from particulate matter and small ore fragments to fragments of approximately $1 \mathrm{~g}$ in weight were added to $100 \mathrm{ml}$ of medium. About $50 \%$ of the ore fragments and aggregated particles did not pass a $5 \mathrm{~mm}$ sieve. Where required, supplements added separately and together were elemental sulfur $\left(5 \mathrm{~g} \mathrm{l}^{-1}\right)$ and ferric iron (10 $\mathrm{mM}$ iron, added as ferric sulfate). Where required for controls without microbial activity, benzoic acid (50 $\mathrm{mg} \mathrm{l}^{-1}$ ) was added to un-inoculated medium to prevent growth of mineral-oxidizing bacteria that were indigenous to the ore samples. Flasks were shaken at a speed (75 rpm), which circulated the medium but did not cause movement of large particles and ore fragments. Anoxic conditions were established in flasks by passing $5 \% \mathrm{v} / \mathrm{v} \mathrm{CO}_{2}$ in $\mathrm{N}_{2}$ through the medium for $2 \mathrm{~h}$ before the flasks were sealed. For a period of aeration, SubaSeals were replaced with foam bungs to allow free gas exchange. Restoration of anoxic conditions involved re-gassing the culture medium with $5 \% \mathrm{v} / \mathrm{v} \mathrm{CO}_{2}$ in $\mathrm{N}_{2}$ for an hour, with replacement of the foam bungs with SubaSeals. Inoculation was with $5 \mathrm{ml}$ of At. ferrooxidans previously grown anaerobically with sulfur and ferric iron. For a culture that was aerated continuously, the inoculum was previously grown aerobically with sulfur. Metals in solution were measured by atomic absorption spectrophotometry.

\subsection{Shaken flasks with secondary (part leached) ore at $47^{\circ} \mathrm{C}$}

Cultures were established with part-leached ore as described for $30^{\circ} \mathrm{C}$ but were incubated at $47^{\circ} \mathrm{C}$ after inoculation with the pyrite-enrichment culture (which was derived from the heap ore fragments and associated precipitates) in place of At. ferrooxidans. This culture appeared to comprise only Sb. thermosulfidooxidans in significant numbers. Where periods of aeration were required, the flasks were gassed with $5 \% \mathrm{v} / \mathrm{v} \mathrm{CO} 2$ in air in order to retain the elevated carbon dioxide concentration required for optimum growth of Sulfobacillus species, with SubaSeals replacing the foam bungs used at $30^{\circ} \mathrm{C}$. At the indicated times of the imposed changes in the atmospheres of flasks (aerobic/anaerobic growth switching), the culture medium was removed. $10 \mathrm{ml}$ was returned to each flask to maintain an active culture. $90 \mathrm{ml}$ was filtered and the collected solids were returned to the flasks with $90 \mathrm{ml}$ of fresh culture medium (at pH 1.8). This procedure was to remove the iron in solution so that subsequent anaerobic sulfur oxidation would require iron from ferric iron-rich precipitates rather than utilize the portion of ferric iron that remained in solution after the aerated phases.

\subsection{Shaken flasks with ore at $70^{\circ} \mathrm{C}$}

Ore fragments (60 g) prepared for heap leaching, but not previously leached, were placed in flasks (2.3 l volume) with $600 \mathrm{ml}$ of the mineral salts medium. The ore fragments were of a roughly consistent size with no fine particles and an average fragment weight of $0.75 \mathrm{~g}$. Initially, six flasks were incubated at $70^{\circ} \mathrm{C}$ for $20 \mathrm{~h}$ before 
the medium was decanted and aliquots were retained for analysis. Pre-warmed medium (570 ml, $\left.70{ }^{\circ} \mathrm{C}, \mathrm{pH} 1.7\right)$ was then added to the ore fragments before inoculation with 'Sulfolobus' strain J2. The inoculum was grown with aeration on sulfur to a cell number of $2.3 \times 10^{8} \mathrm{ml}^{-1}$, at which time the $\mathrm{pH}$ was 1.3 . A $5 \% \mathrm{v} / \mathrm{v}$ inoculum gave an initial cell number of $1.15 \times 10^{7}$ cells $\mathrm{ml}^{-1}$. All flasks were gassed with $5 \% \mathrm{v} / \mathrm{v} \mathrm{CO}$ in air $\left(500 \mathrm{ml} \mathrm{min}^{-1}\right)$ for 30 min before sealing with SubaSeals. After a period of growth with aeration (Section 3.4), three of the cultures were made anoxic by gassing the medium with $5 \% \mathrm{v} / \mathrm{v} \mathrm{CO}_{2}$ in $\mathrm{N}_{2}\left(500 \mathrm{ml} \mathrm{min}^{-1}\right)$ for 30 min and sealing the flasks with SubaSeals. The other three flasks were also sealed but after gassing with $5 \% \mathrm{v} / \mathrm{v} \mathrm{CO}_{2}$ in air $\left(500 \mathrm{ml} \mathrm{min}^{-1}\right)$. Flasks were incubated at $70^{\circ} \mathrm{C}$ in an orbital shaker with gentle shaking, which was sufficient to circulate the medium but not to move the ore fragments. The $\mathrm{pH}$ was maintained between 1.8 and 2.1 (Section 3.4) by addition of $\mathrm{H}_{2} \mathrm{SO}_{4} 5 \%$ $\mathrm{v} / \mathrm{v})$.

When anoxic conditions were introduced to some flasks, the medium was decanted from the solids in all flasks and aliquots retained for analysis. Any suspended solids including precipitated iron compounds were collected by centrifugation, air-dried and reserved for subsequent acid digestion. Pre-warmed fresh medium (540 ml) was added to the ore fragments in each flask. The first time anoxic conditions were imposed, $60 \mathrm{ml}$ of the decanted medium was retained from each flask and returned with the fresh medium to ensure maintenance of an active culture. At

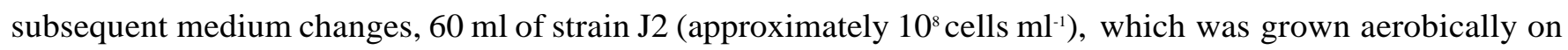
sulfur, was used to supplement the microbial population. All flasks were re-sealed with SubaSeals. Aerated cultures were re-gassed for a short period (one to two minutes) after each sampling to preclude any overdepletion of oxygen. Anoxic conditions were restored where required by repetition of the previous gassing with $\mathrm{CO}_{2} / \mathrm{N}_{2}$.

At the end of the incubation, the medium and ore fragments were separated. The fragments were washed with deionised water. Following centrifugation ( $8000 \mathrm{rpm}, 10 \mathrm{~min}$ ), the solids were ground to fine particles in a ball-mill before drying and weighing. Hot acid digestion $\left(\mathrm{HCl} / \mathrm{HNO}_{3}\right)$ of solid residues together with the small amounts of particles separated from solution at the medium changes was followed by measurement of residual and precipitated target metals. Time course solution samples, bulk solution samples from medium replacements and residue washings from centrifugations were also analysed to determine metal concentrations in solution during the experiment.

\subsection{Ore column leaching}

The columns used were described previously (Norris et al., 2012a). Each column contained $0.7 \mathrm{~kg}$ of partleached ore, which comprised three size fractions after a preliminary sorting. These fractions contained fragments with mean weights of $1 \mathrm{~g}$ ( $50 \%$ of the ore fragments per column), $0.25 \mathrm{~g}$ (25\%) and finer particles (25\%). Irrigation solution dripped centrally onto ore columns at a flow rate of $0.15 \mathrm{l} \mathrm{day}^{-1}$, corresponding to a surface application rate of approximately $4 \mathrm{l} \mathrm{m}^{-2} \mathrm{~h}^{-1}$. The irrigation solution contained $\left(\mathrm{NH}_{4}\right)_{2} \mathrm{SO}_{4}\left(20 \mathrm{mg} \mathrm{l}^{-1}\right), \mathrm{MgSO}_{4^{-}}$ $7 \mathrm{H}_{2} \mathrm{O}\left(40 \mathrm{mg} \mathrm{l}^{-1}\right)$ and $\mathrm{K}_{2} \mathrm{HPO}_{4}\left(10 \mathrm{mg} \mathrm{l}^{-1}\right)$ and was adjusted to $\mathrm{pH} 1.5$ with $\mathrm{H}_{2} \mathrm{SO}_{4}$. There was no solution recycling 
through columns. Columns were gassed from their base with $50 \mathrm{ml} \mathrm{min}{ }^{-1}$ of either $5 \% \mathrm{v} / \mathrm{v} \mathrm{CO}_{2}$ in air or with $5 \% \mathrm{v} / \mathrm{v}$ $\mathrm{CO}_{2}$ in $\mathrm{N}_{2}$ to maintain aerated or anoxic conditions respectively.

Columns were inoculated with the enrichment culture established from the previously part-leached ore sample. Two columns were aerated throughout the leaching and were inoculated with cells grown aerobically and two columns that were initially anoxic were inoculated with cells grown anaerobically (on sulfur plus ferric iron). Inocula contained about $2 \cdot 10^{7}$ cells $\mathrm{ml}^{-1}$ after removal of residual sulfur by filtration through sintered glass filters. Inocula ( $250 \mathrm{ml}$ ) were added to columns to cover the ore bed. After $1 \mathrm{~h}$, the columns were drained and the irrigation flow started.

\section{Results and discussion}

\subsection{Selection of organisms for anaerobic growth}

The anaerobic activities of various mesophiles, moderate thermophiles and thermophiles were compared during growth with sulfur and ferric iron. The production of ferrous iron (Fig. 1) is discussed below. Growth of strains selected for further work (At. ferrooxidans, Sb. thermosulfidooxidans and “Sulfolobus”-like strain J2) was also measured in terms of biomass volume and cell numbers and in each case found to be proportional to the ferrous iron production (data not shown).

\subsubsection{Mesophiles}

At. ferrooxidans produced ferrous iron during anaerobic growth on sulfur as expected (Fig. 1) and this strain was used for further work with the ore. The sulfur-oxidizing At. thiooxidans and “Acidithiobacillus"' strain V1 did not show any reproducible or extensive ferric iron reduction (data not shown).

\subsubsection{Moderate thermophiles}

Anaerobic growth of At. caldus and Sb. acidophilus could not be established with sulfur and ferric iron at $47^{\circ} \mathrm{C}$. Growth of Sulfobacillus strain G1 (at $52^{\circ} \mathrm{C}$ ) and “Acidithiomicrobium”' strain P2 (at $47^{\circ} \mathrm{C}$ ) could be maintained through serial cultures but both of these species showed poorer activity than some strains of $S b$. thermosulfidooxidans (Fig. 1). An enrichment culture established from previously part-leached ore from the commercial heap and an isolate of Sb. thermosulfidooxidans from a laboratory bioreactor fed with a copper concentrate showed similar capacities for autotrophic, anaerobic growth with sulfur and ferric iron (Fig. 1). The type strain of Sb. thermosulfidooxidans (DSM 9293) failed to grow anaerobically with sulfur and ferric iron (data not shown), although growth of this strain anaerobically with ferric iron and glycerol has been reported (Stott et al., 2000). The enrichment culture from the ore heap sample, which appeared to contain only Sb. thermosulfidooxidans, was selected for further work. The apparent lack of diversity in this enrichment culture might have represented the population at the ore collection site or might have resulted from a lack of survival of other 
species in the ore sample, which had at least partially dried during collection and transport. Sb. thermosulfidooxidans was previously found in a demonstration ore heap at Talvivaara as part of a mixed population (Halinen et al., 2012).

\subsubsection{Thermophiles}

The anaerobic activities of eight cultures (from widespread geographical locations, all capable of pyrite oxidation at $75-80^{\circ} \mathrm{C}$ ) were compared (data not shown). There was no apparent pattern to the phylogenetic distribution of this activity among these thermoacidophilic archaea. Poor activity was shown by two cultures dominated by Acidianus species (from Yellowstone National Park, USA and from Milos, Greece) and by a culture of Metallosphaera sp. (from China). The reproducibility of these observations is uncertain, as each of these cultures showed reasonable initial activity before serial subculture. One “'Acidianus sp.” (strain MS2) was very active through serial subcultures (data not shown). Strain J1 (a Metallosphaera sp. from a hot spring in Java) and strain J2 (an un-named "Sulfolobus"like species also from Java) were consistently most active with the most extensive reduction of ferric iron. Strain J2 was selected for further work. The complete solubilization of ferric iron that had precipitated when added to the medium was obtained more readily with strain $\mathrm{J} 2$ at $75^{\circ} \mathrm{C}$ than with moderate thermophiles (Fig. 1).

\subsection{Shaken flasks at $30{ }^{\circ} \mathrm{C}$ with previously part-leached ore}

The capacity of the previously part-leached ore to support anaerobic microbial activity was assessed initially using At. ferrooxidans that was already adapted to anaerobic growth with sulfur and ferric iron. Ferrous iron was produced with hardly a lag phase when the ore was supplemented with sulfur together with ferric iron (Fig. 2). In the absence of these supplements but with inoculation, the most rapid ferrous iron generation occurred after a few days. The production of ferrous iron in un-inoculated medium slowed sooner than in inoculated medium and about $20 \%$ of the iron in solution remained as ferric iron in the absence of microbial iron reduction. Addition of sulfur stimulated bacterial activity and ferric reduction more than the ferric iron supplement. With aeration after 19 days of anoxic conditions, iron in solution remained as ferrous iron in un-inoculated medium but was rapidly oxidized in inoculated medium. With re-imposition of anoxic conditions, rapid ferric iron reduction was again established in inoculated cultures. The rate of ferrous iron production after the aeration period was similar in cultures without supplements and with ferric iron supplementation. In contrast, the supplementation with sulfur resulted in more rapid and extensive ferrous iron production (Fig. 2).

The effect of anoxic conditions was initially to decrease leaching of zinc and nickel (Fig. 3) and of copper (data not shown) in comparison to leaching in a continuously aerated culture. On introduction of aeration to previously anoxic cultures, there was some precipitation of iron when ferrous iron was oxidized (the culture $\mathrm{pH}$ was between $\mathrm{pH} 2.1$ and 2.5), but most iron remained in solution as ferric iron to contribute to rapid leaching of the target metals and probably to some re-solubilization of previously leached metals that were lost from solution towards the end of the initial anoxic period. In cultures initially exposed to an anoxic phase, leaching of nickel and zinc by the end of the short aerated phase was at least equal to and greater respectively than that in the 
continuously aerated culture, although replicates were not tested to confirm this at this temperature. A second anoxic phase halted leaching of the target metals while conversion of ferric iron in solution to ferrous iron occurred and further iron was solubilized. The more rapid and extensive ferrous iron production that was seen with supplementation of the medium with sulfur was not reflected in the concentrations of target metals in solution. At the end of the aeration phase, the total (ferric) iron in solution was 35\% higher in the sulfur-supplemented culture whereas there was a similar concentration of zinc in solution but about 20\% less nickel and 55\% less copper (data not shown).

\subsection{Shaken flasks at $47^{\circ} \mathrm{C}$ with previously part leached ore}

The time courses of iron in solution at $47^{\circ} \mathrm{C}$ show the aggregates of iron removed from solids during the incubations: these total iron removal values were calculated by addition of iron concentrations in solutions at each of the times when $90 \%$ of the culture medium was removed from flasks and replaced with new medium, and the gas composition in head spaces of flasks were changed (Fig. 4).

Iron in solution during the initial aerated phase was ferrous iron in un-inoculated controls and remained as ferrous iron throughout the incubation while iron in solution in continuously aerated, inoculated flasks was ferric iron throughout. There was more iron in solution in un-inoculated medium than in continuously aerated cultures where some precipitation occurred (Fig. 4). The extensive release of iron into solution with inoculated flasks during anoxic phases was as ferrous iron while only ferric iron was present when these flasks were aerated. The final aerated phase was extended for $50 \mathrm{~h}$ beyond the illustrated data, at which time the total iron removed from the continuously aerated flasks was about $35 \%$ of that available compared to $69 \%$ removed when there were anoxic phases during the incubation (data not shown). When an anoxic phase was imposed at the start of an incubation to reverse the order of the first two (aerated and anoxic) phases, the final iron removal was 76\% (data not shown).

After some solubilization of nickel, zinc and copper during the initial aerated period, leaching of these metals did not occur in the anoxic phases but was rapid following re-aeration (data not shown), as seen previously at $30^{\circ} \mathrm{C}$ (Fig. 3). Some copper was lost from solution during anoxic phases at $47^{\circ} \mathrm{C}$, but was rapidly recovered with re-aeration. At the end of the incubation, yields in solution were about $90 \%$ for nickel, and zinc and $70 \%$ for copper. However, in contrast to iron, no significant differences between the extent of the leaching of these metals in flasks with or without anoxic phases could be determined because of variation between replicates which resulted from use of a limited quantity of ore fragments with variable composition. In order to investigate the influence of anoxic periods further, larger ore samples and more replicates were examined at higher temperature.

\subsection{Shaken flasks at $70^{\circ} \mathrm{C}$ with the polymetallic sulfide ore}

“Sulfolobus" strain J2 was selected after culture screening at $75^{\circ} \mathrm{C}$ (Section 3.1.3). In contrast to the shaken flask experiments with pre-leached ore at lower temperatures, the use of un-leached ore at $70^{\circ} \mathrm{C}$ required that the 
first phase of growth was under aeration. This allowed iron oxidation and precipitation to provide the ferric ironcontaining precipitate that was the electron acceptor for anaerobic growth in those cultures that had an anoxic phase subsequently imposed. After initially similar leaching in all aerated cultures, greater iron solubilization occurred during anoxic phases where these were imposed (Fig. 5), with iron in solution as ferrous iron in contrast to ferric iron in solution in cultures that were maintained with aeration. As with iron in solution at $47^{\circ} \mathrm{C}$ (Fig. 4), the aggregate of metals shown in solution at $70^{\circ} \mathrm{C}$ is the value calculated by addition of concentrations in solution when the medium was replaced each time flask head spaces were re-gassed (Fig. 5). The ore fragments were visibly coated with red/ brown iron-rich precipitate after each phase of aeration while those fragments exposed to anoxic conditions returned to their initial grey/black colour with removal of the majority of the precipitate from the surface. Total iron removal in solution after 70 days was $60 \%$ increased in cultures with anoxic phases compared to those which were aerated continuously while nickel, copper and zinc leaching was increased by between 5\% and 8\% (Fig. 6). Over the course of leaching, the $\mathrm{pH}$ was generally maintained at about $\mathrm{pH} 1.9$, which required an aggregate addition of $95 \mathrm{ml}$ of $5 \% \mathrm{v} / \mathrm{v} \mathrm{H}_{2} \mathrm{SO}_{4}$ to each continuously aerated culture and $65 \mathrm{ml}$ to those with aerated/anoxic cycles (with four medium changes during the incubation, this acid was added to a total of 31 of growth medium per culture).

\subsection{Ore columns with secondary (part leached) ore at $47^{\circ} \mathrm{C}$}

Two ore columns were aerated throughout leaching at $47^{\circ} \mathrm{C}$ after inoculation with the ore heap enrichment culture, which had been grown aerobically on sulfur. Two more ore columns that were initially anoxic before later aeration were inoculated with the culture grown anaerobically with sulfur and ferric iron. The general behaviour and pattern of iron solubilization was similar in duplicated columns: the data from one of each pair are shown for clarity to illustrate ferrous/ferric iron ratios in effluent solutions (Fig. 7). The concentration of iron that was readily solubilized and initially flushed out of columns reached almost $3 \mathrm{~g} \mathrm{l}^{-1}$ (not shown because of the truncated graph axis, Fig. 7). A pH of around 3 for the effluent from the aerated column for the first twenty days resulted in precipitation of oxidized iron compounds restricting the iron concentration in solution. The iron released from all columns was essentially ferrous iron for almost 100 days (Fig. 7). This reflected the absence of air in the anoxic ore column and the reaction of ferric iron with ore while sulfides were readily available and accessible in the early stages of leaching. On aeration of the initially anoxic ore column after 63 days, rapid bacterial oxidation of ferrous iron resulted in precipitation of ferric compounds, replicating the pattern seen initially with the continuously aerated column. Eventually, ferrous iron was essentially absent from all effluents (Fig. 7) when readily accessible ore was mostly oxidized and some ferric iron was maintained in solution with effluent $\mathrm{pH}$ values between $\mathrm{pH} 1.9$ and 2. The comparatively high concentrations of iron (ferrous iron) in the effluent during the early leaching of the anoxic ore columns was reflected in the higher total iron removal compared to that from ore columns that were continuously aerated (Fig. 8). The lag before rapid ferrous iron release in one of the initially anoxic columns (Fig. 8) and greater initial release of nickel from this column (Fig. 9) appeared to result from some unintentional exposure of ore to air, which was ended by tightening all connections and seals. 
The effects of aeration and an anoxic phase on zinc leaching (data not shown) and nickel leaching (Fig. 9) were similar. In contrast, rapid and extensive copper leaching did not occur from any columns until after about 100 days. Effluents from all columns became gradually more acidic throughout leaching with $\mathrm{pH}$ values of just over 3 for the first few days, $\mathrm{pH}$ 2.3-2.4 after about 100 days and $\mathrm{pH} 1.9-2$ at the end of leaching. A critical $\mathrm{pH}$ of about 2.3-2.5 for copper release from pyrrhotite-rich nickel sulfides has been observed previously (Maley et al. 2009a,b; Watling et al., 2009; Norris et al., 2012b). Copper has also been observed to precipitate in the ore heap at Talvivaara after initial leaching (Riekkola-Vanhanen, 2013). There was rapid solubilization of nickel after introduction of aeration after 63 days to both previously anoxic columns. Any effects of anoxic periods on the yields of target metals were uncertain because leaching was still occurring at the end of the incubation and because of variations between ore columns and an insufficient number of replicates. One of the duplicate columns with an anoxic initial period showed the greatest nickel extraction while the other showed the lowest extraction in comparison to nickel release from columns aerated continuously (Fig. 9). Therefore, an initially anoxic period was not necessarily detrimental to subsequent nickel extraction and the desired, enhanced removal of iron was achieved. The influence of furthervariationsinthe timing and duration of anoxic periods could be investigated.

Similar ore columns were also examined at $30^{\circ} \mathrm{C}$ but with only duplicate columns aerated continuously and with two columns with different timing of anoxic periods, so there were insufficient replicates to determine effects on yields of target metals after 260 days leaching. In general, the pattern of target metal leaching was similar to that seen at $47^{\circ} \mathrm{C}$ with nickel and zinc leaching slowed during anoxic phases but stimulated on re-aeration with no eventual detriment to the yields from extended periods of anoxic conditions (initially 80 days with one column). In contrast to the leaching at higher temperature where iron precipitation was greater, iron removal was only very slightly higher from columns that had anoxic phases imposed.

\section{Conclusions}

1. Different acidophilic microorganisms were used at close to their individual optimum temperatures for growth to show microbial reduction of ferric iron under anoxic conditions over a temperature range of 30$75^{\circ} \mathrm{C}$ : these were the mesophile At. ferrooxidans, moderate thermophiles (of which Sb. thermosulfidooxidans was particularly active) and, at the higher temperatures, several thermoacidophilic archaea.

2. Much greater removal of iron from a poly-metallic ore environment was achieved at $47^{\circ} \mathrm{C}$ in shaken flasks (with medium changes) and in ore columns (with continuous irrigation) when anoxic phases were introduced compared to when aeration was continuous. Any effect of this increased iron removal on yields of target metals in solution was not clear at $47^{\circ} \mathrm{C}$, because of variations between replicates. This demonstration of enhanced removal of iron from ore leaching columns was not coupled with any study of how the percolation was affected, leaving further work required to determine the potential merits or disadvantages of enhanced iron removal in ore heap leaching. 
3. Iron removal was also much greater at $70{ }^{\circ} \mathrm{C}$ with "Sulfolobus" strain $\mathrm{J} 2$ in shaken flasks (with medium changes) when anoxic phases were introduced. Iron-rich precipitates were visibly removed from ore fragment surfaces during the anoxic phases and increased yields of nickel, zinc and copper were obtained when anoxic phases alternated with aeration.

4. The mechanisms of anaerobic microbial activity were not addressed in this work. Oxygen was excluded from ore columns to create anoxic conditions but some oxygen penetration would be likely in an ore heap. It is not known if microbial anaerobic sulfur oxidation requires totally anoxic conditions or whether there is a graded response to the presence of a limited amount of air. Any such response might differ between organisms because different anaerobic oxidation mechanisms will be present in the different phylogenetic groups used here.

\section{Acknowledgements}

This work was funded by the European Commission Belgium under the Sixth Framework Programme for Research and Development (EU Promine Project, FP7-CP-IP, Project No. 22859) and by BHP Billiton Chile Inc. with the support of Carol Davis-Belmar and Hannes Strauss. We are grateful to the Talvivaara Mining Company and Marja Riekkola-Vanhanen for provision of ore samples and analyses.

\section{References}

Bridge, T., Johnson, D., 1998. Reduction of soluble iron and reductive dissolution of ferric iron-containing minerals by moderately thermophilic iron-oxidising bacteria. Appl. Environ. Microbiol. 64, 2181-2186.

Brock, T.D., Gustafson, S., 1976. Ferric iron reduction by sulfur- and iron-oxidising bacteria. Appl. Environ. Microbiol. 32, 567-571.

Burton, N.P., Norris, P.R., 2000. Microbiology of acidic, geothermal springs of Montserrat: environmental DNA analysis. Extremophiles 4, 315-320.

Das, A., Mishra, A.K., Roy, P., 1992. Anaerobic growth on elemental sulfur using dissimilar iron reduction by autotrophic Thiobacillus ferrooxidans. FEMS Microbiol. Lett. 97, 167-172.

Davis-Belmar, C.S., Norris, P.R., 2009. Ferrous iron and pyrite oxidation by “Acidithiomicrobium” species. Adv. Mater. Res. 71-73, 271-274.

Donati, E., Pogliani, C., Boiardi, J.L., 1997. Anaerobic leaching of covellite by

Thiobacillus ferrooxidans. Appl. Microbiol. Biotechnol. 47, 636-639.

Goodman, A.E., Babij, T., Ritchie, A.I.M., 1983. Leaching of a sulphide ore by Thiobacillus ferrooxidans under anaerobic conditions. In: Rossi, G., Torma, A.E. (Eds.), Recent Progress in Biohydrometallurgy. Associazione Mineraria Sarda, Iglesias, pp. 361-376.

Halinen, A.K., Beecroft, N.J., Määttä, K., Nurmi, P., Laukkanen, K., Kaksonen, A.H., Riekkola-Vanhanen, M., Puhakka, J.A., 2012. Microbial community dynamics during a demonstration-scale bioheap leaching operation. Hydrometallurgy 125-126, 34-41.

Maley, M., van Bronswijk, W., Watling, H.R., 2009a. Leaching of a low-grade, copper- nickel sulfide ore. 2. Impact of aeration and $\mathrm{pH}$ on $\mathrm{Cu}$ recovery during abiotic leaching. Hydrometallurgy 98, 66-72.

Maley, M., van Bronswijk, W., Watling, H.R., 2009b. Leaching of a low-grade, copper-nickel sulfide ore. 3. Interactions of $\mathrm{Cu}$ with selected sulfide minerals. Hydrometallurgy 98, 73-80.

Norris, P.R., Davis-Belmar, C.S., Brown, C.F., Calvo-Bado, L.A., 2011. Autotrophic, sulfur-oxidizing actinobacteria in acidic environments. Extremophiles 15, 155- 163.

Norris, P.R., Brown, C.F., Caldwell, P.E., 2012a. Ore column leaching with thermophiles: II, polymetallic sulfide ore. Hydrometallurgy 127-128, 70-76.

Norris, P.R., Calvo-Bado, L.A., Brown, C.F., Davis-Belmar, C.S., 2012b. Ore column leaching with thermophiles: I, Copper sulfide ore. Hydrometallurgy 127-128, 62-69.

Norris, P.R., Burton, N.P., Clark, D.A., 2013. Mineral sulfide concentrate leaching in high temperature bioreactors. Miner. Eng. 48, 10-19. 
Pronk, J.T., De Bruyn, J.C., Bos, P., Kuenen, J.G., 1992. Anaerobic growth of Thiobacillus ferrooxidans. Appl. Environ. Microbiol. 58, 2227-2230.

Riekkola-Vanhanen, M., 2013. Talvivaara mining company - from a project to a mine. Miner. Eng. 48, 2-9.

Simmons, S., Norris, P.R., 2002. Acidophiles of saline water at thermal vents of Vulcano, Italy. Extremophiles 6, 201207.

Stott, M.B., Watling, H.R., Franzmann, P.D., Sutton, D., 2000. The role of iron-hydroxy precipitates in the passivation of chalcopyrite during bioleaching. Miner. Eng. 13, 1117-1127.

Watling, H.R., Elliot, A.D., Maley, M., van Bronswijk, W., Hunter, C., 2009. Leaching of a low-grade, copper-nickel sulfide ore. 1. Key parameters impacting on Cu recovery during column leaching. Hydrometallurgy 97, $204-212$. 


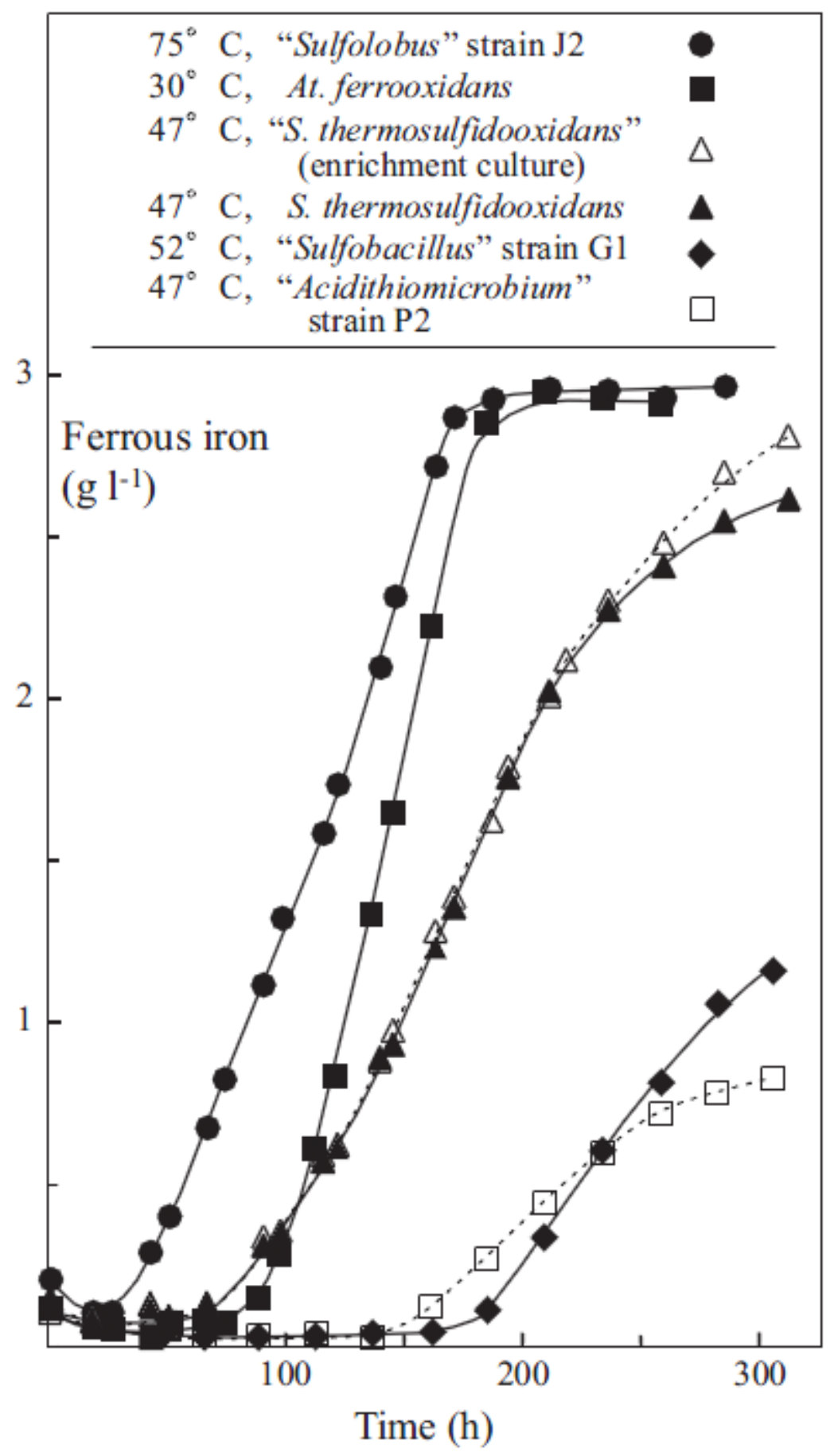

Fig. 1. Production of ferrous iron during anaerobic growth of acidophiles with sulfur and ferric iron at the indicated temperatures in shaken flasks. 


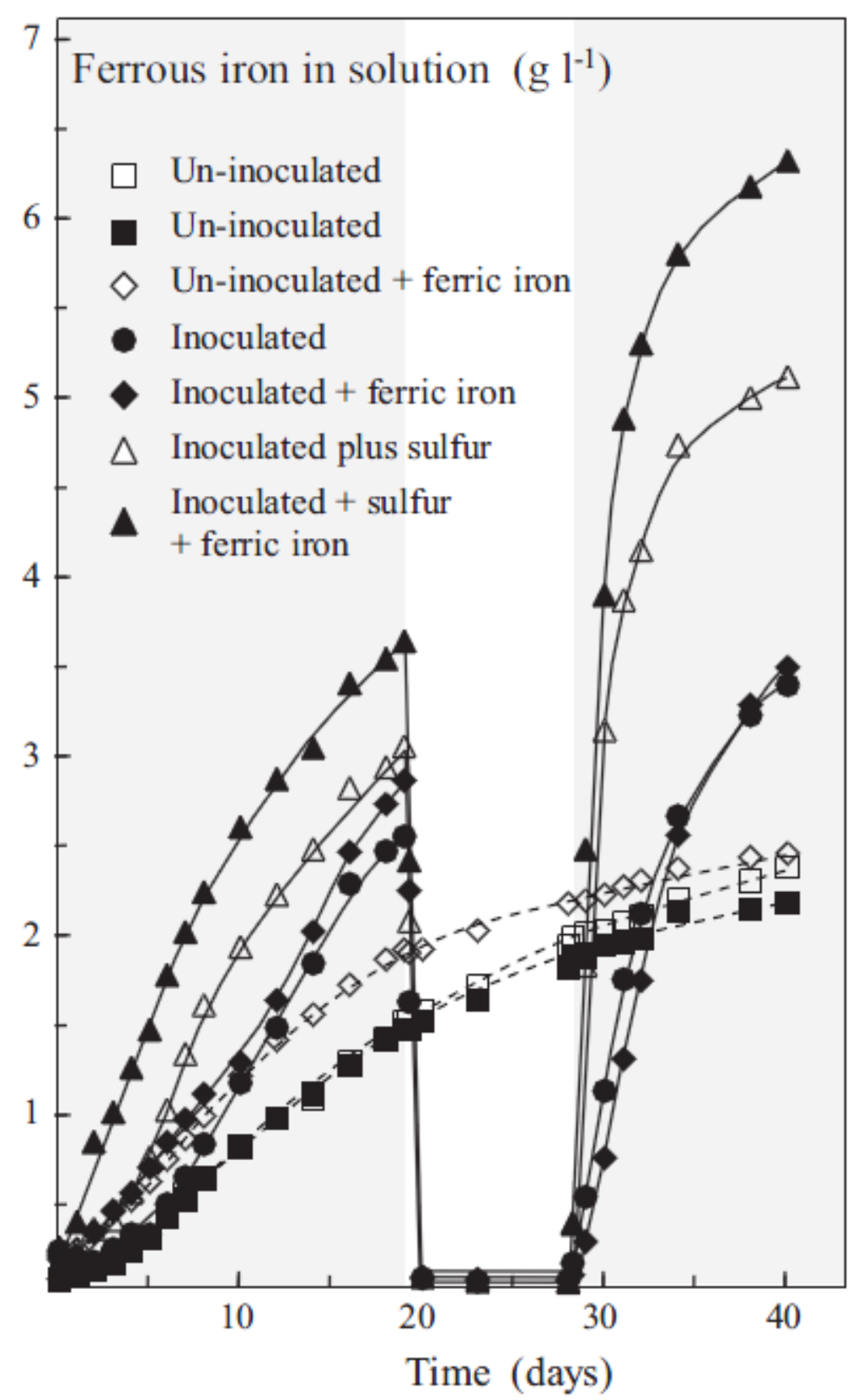

Fig. 2. Ferrous iron in solution during growth of At. ferrooxidans at $30{ }^{\circ} \mathrm{C}$ during anaerobic and aerobic growth with the previously part-leached polymetallic sulphide with and without addition of ferric iron and sulfur. The shaded background indicates anoxic periods. 


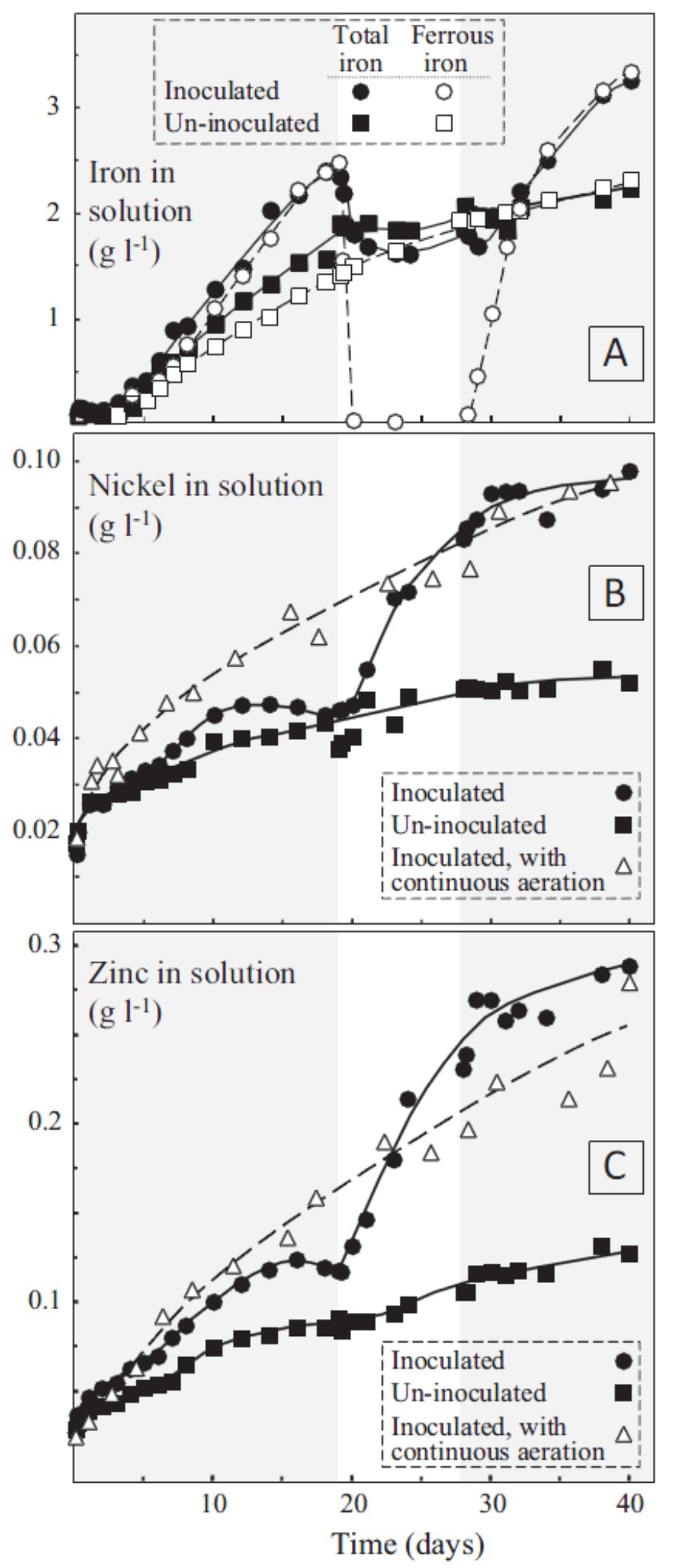

Fig. 3. The effect of aeration and anoxic conditions on solubilization of (A) iron, (B) nickel and (C) zinc from a previously part-leached polymetallic sulfide ore during growth of At. ferrooxidans at $30{ }^{\circ} \mathrm{C}$. The shaded background indicates anoxic periods, with the exception of one culture that was aerated continuously (D, in Sections B and C only). 


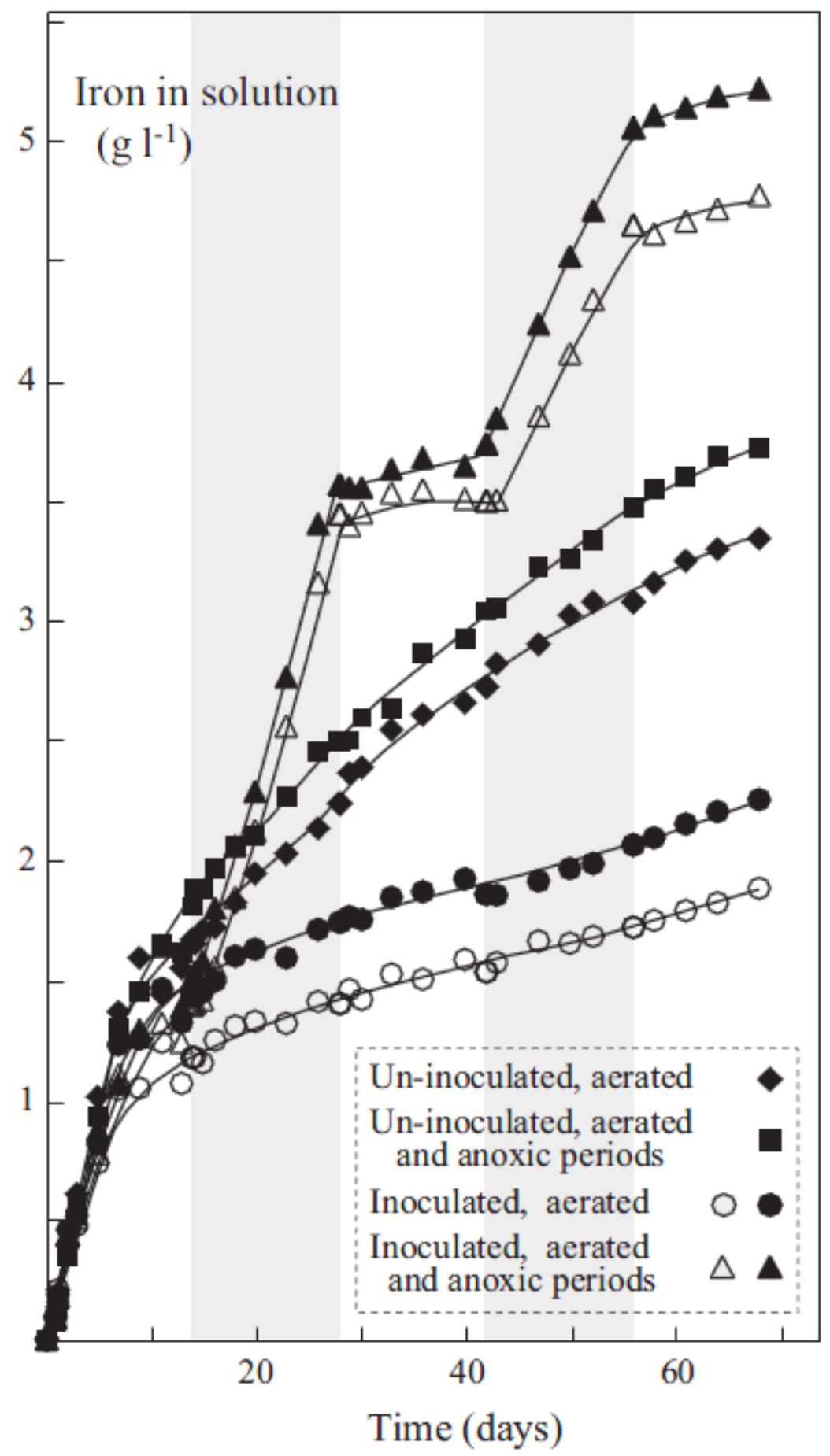

Fig. 4. The total iron leached into solution from the previously part-leached polymetallic sulfide with a Sb.

thermosulfidooxidans-dominated enrichment culture in shaken flasks at $47^{\circ} \mathrm{C}$. Duplicates are shown for cultures which were aerated continuously or with aerated/anoxic periods. The shaded background indicates anoxic periods, which were applied only to one pair of duplicate cultures and an uninoculated control, as indicated. 

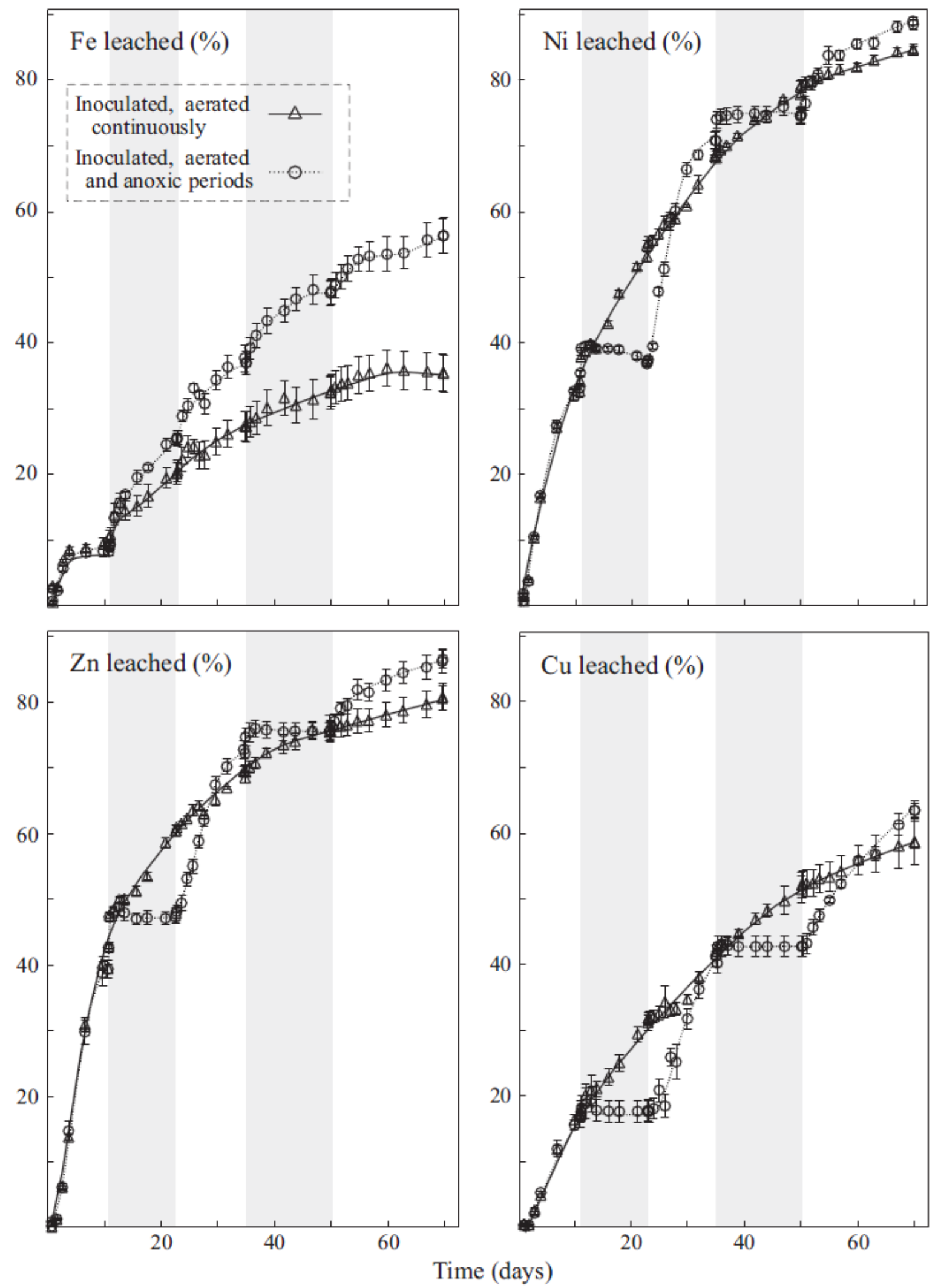

Fig. 5. The effect of aeration and anoxic conditions on solubilization of iron, nickel, zinc and copper from the polymetallic sulfide ore during growth of “'Sulfolobus"' strain $\mathrm{J} 2$ at $70{ }^{\circ} \mathrm{C}$. The shaded background indicates periods when anoxic conditions were applied to three of the six cultures, as indicated. Error bars are standard error of the mean for replicate flasks $(n=3)$. 


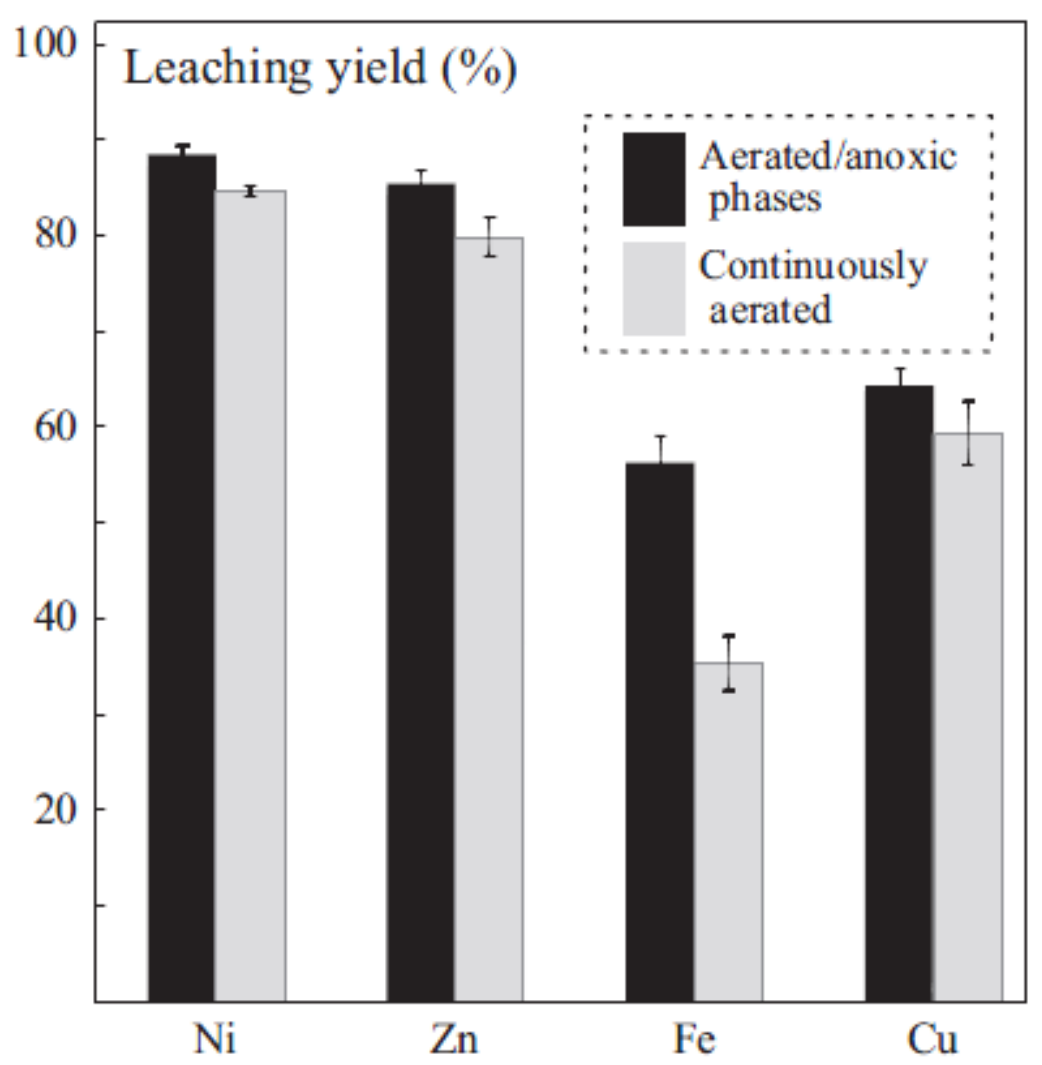

Fig. 6. Yields of nickel, zinc, iron and copper in solution after leaching of primary polymetallic sulfide ore for 70 days by “'Sulfolobus"' strain J2 (illustrated by Fig. 5). Error bars indicate standard error of the mean for replicate cultures (n $=3)$. 


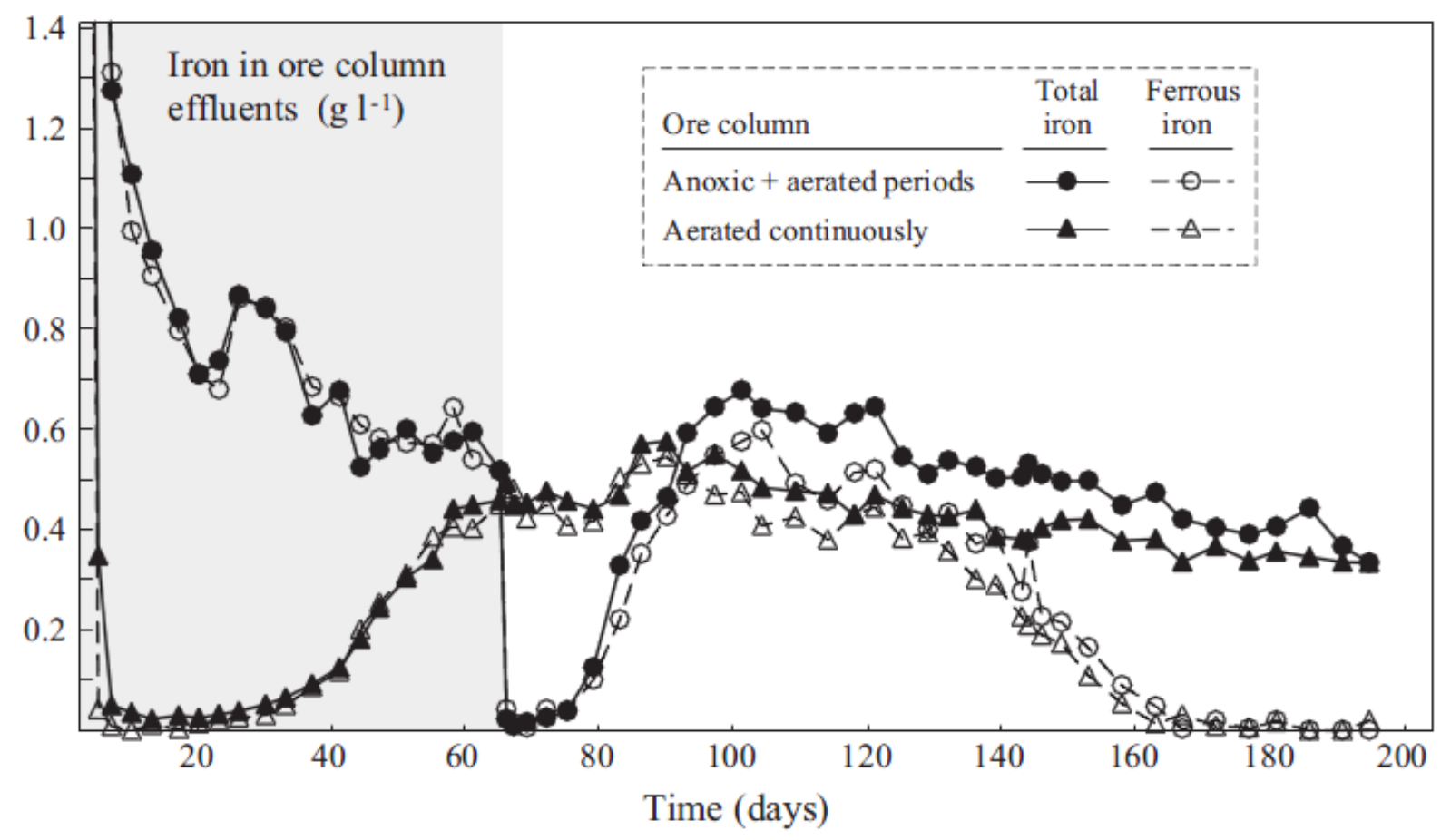

Fig. 7. Iron in effluents at $47^{\circ} \mathrm{C}$ from two ore columns which were inoculated with an ore heap enrichment culture and gassed with $5 \% \mathrm{v} / \mathrm{v} \mathrm{CO}_{2}$ in air, apart from the first 63 days (shaded background) when aeration was replaced with 5\% $\mathrm{v} / \mathrm{v} \mathrm{CO}_{2}$ in $\mathrm{N}_{2}$ for one of the columns, as indicated. 


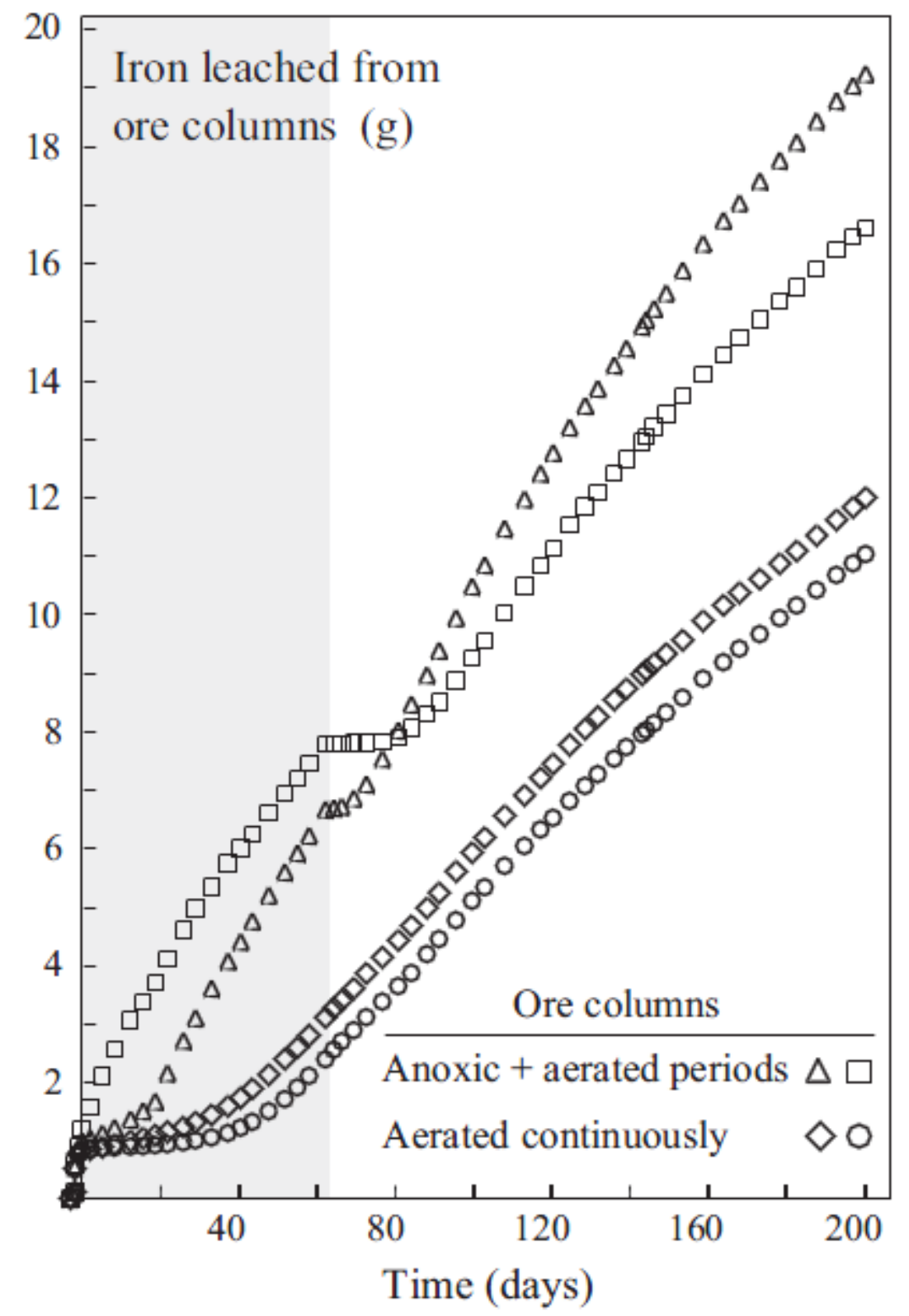

Fig. 8. Total iron leached from four ore columns which were inoculated with the ore heap enrichment culture at $47^{\circ} \mathrm{C}$. The columns were gassed with $5 \% \mathrm{v} / \mathrm{v} \mathrm{CO}_{2}$ in air, apart from the first 63 days (shaded background) when two of the columns were gassed with $5 \% \mathrm{v} / \mathrm{v} \mathrm{CO}_{2}$ in $\mathrm{N}_{2}$, as indicated. 


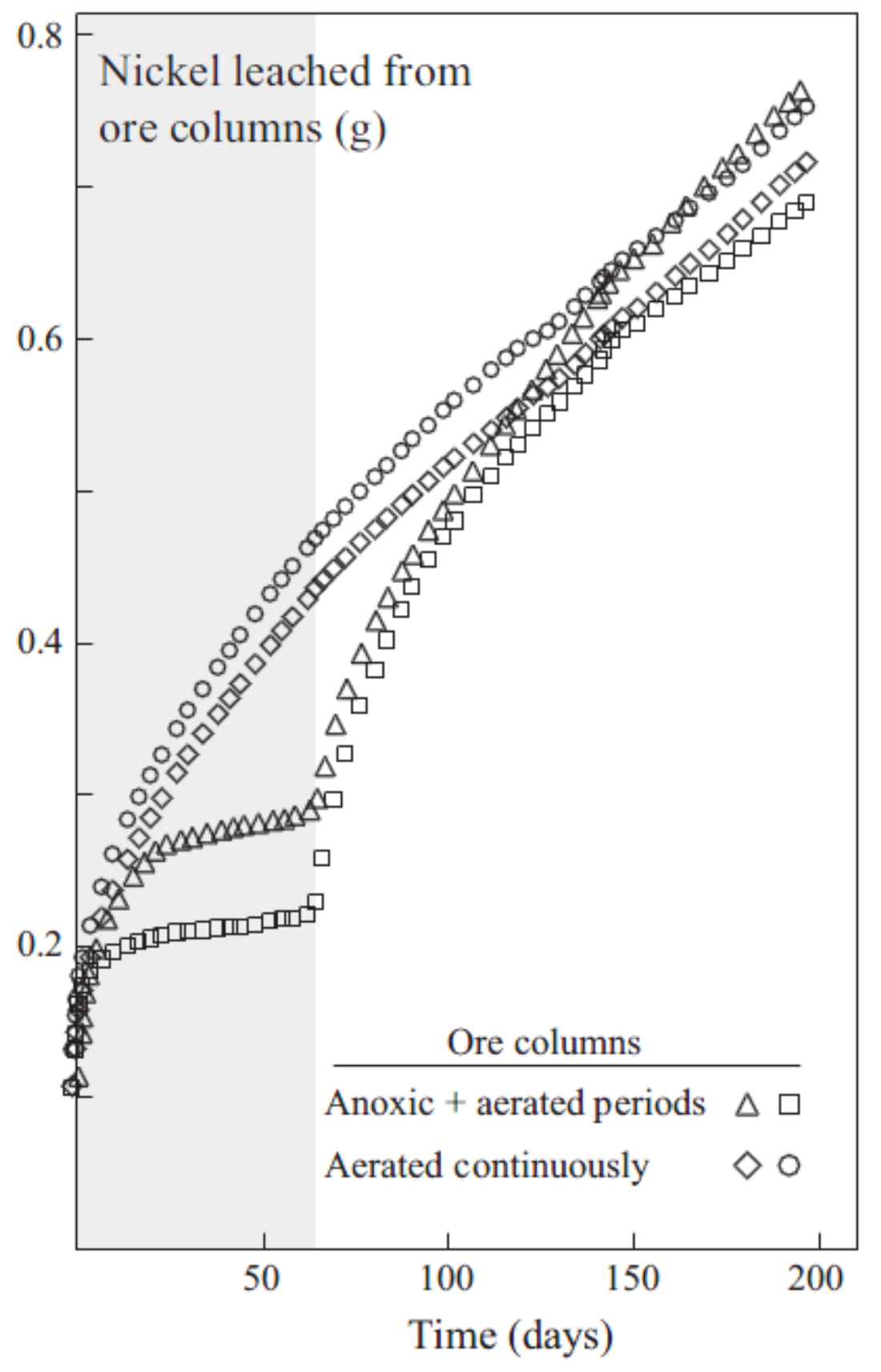

Fig. 9. Nickel leached from ore columns at $47^{\circ} \mathrm{C}$. Four columns were inoculated with the ore heap enrichment culture and gassed with $5 \% \mathrm{v} / \mathrm{v} \mathrm{CO}_{2}$ in air, apart from the first 63 days (shaded background) when two of the columns were gassed with $5 \% \mathrm{v} / \mathrm{v} \mathrm{CO}_{2}$ in $\mathrm{N}_{2}$, as indicated. 